\title{
Male Infertility- Current Concepts and Advances in Evaluation and Management- A Review
}

\section{Joseph Philipraj S* and Keerthi Rams}

Department of Urology, Mahatma Gandhi Medical College and Research Institute, Sri Balaji Vidyapeeth University, India

Corresponding author: Joseph Philipraj S, Professor Department of urology, MGMCRI, Sri Balaji Vidyapeeth University, Pondicherry, India, Email: josephphilipraj@gmail.com

\section{Review Article}

Volume 3 Issue 3

Received Date: July 25, 2018

Published Date: August 22, 2018

\section{Abstract}

Globally Infertility and problems of impaired fecundity have been a concern. Which affects 8-12\% of couples worldwide of all infertility cases, approximately $40-50 \%$ is due to "male factor" infertility and as many as $2 \%$ of all men will exhibit suboptimal sperm parameters. The cause is multifactorial. The rate of infertility in developing countries is markedly higher. In many a cases there is no definite etiology and it is termed as "Idiopathic Male Infertility. However research in the field of genetics, proteomics has changed the face of male infertility. This review is done to bring home the newer trends in evaluation and management of male infertility.

Keywords: Male Infertility; Semen parameters; Life style; DNA fragmentation

\section{Introduction}

Global infertility prevalence rates are difficult to determine, due to the presence of both male and female factors. One in every four couples in developing countries had been found to be affected by infertility. In $20-25 \%$ of cases the problem was due to the male partner and in 30 $40 \%$ the problem was predominantly female, in approximately $30 \%$ of cases, abnormalities were found in both partners, and in 15\% no specific factor could be identified [1]. It is also important, when dealing with Infertile couples, to recognize that the duration of infertility is a critical prognostic factor, and in couples with a history of primary infertility of longer than $3 \mathrm{yr}$, the possibility of achieving an unassisted pregnancy is low. Most of the aetiologies of Male Infertility are wellestablished. Recently genetic causes of male infertility are diagnosed more as the field of genomic medicine is advancing. Using principles of evidence-based medicine treatment algorithms that guide clinical management is the need of the hour. Treatment algorithms that provide organized and timely guidelines to the current management of male infertility are essential.

Up to $30 \%$ of infertile men are labelled with idiopathic sperm abnormalities [1]. There is a need to identify the causes of so called Idiopathic infertility before personalized treatment recommendations can be made. Researchers are exploring genomics, proteomics, transcriptomics, and metabolomics in an effort to discover better male fertility biomarkers. Some have redirected their efforts to look at current lifestyle factors and their impact on fertility. Several studies have demonstrated an ominous decline in overall sperm quantity and quality in the last several decades, with some blaming the obesity epidemic as the cause $[2,3]$. 


\section{Semen Analysis}

Cornerstone in evaluation of Male in infertility is Semen analysis. Although analysing semen samples can provide valuable information about the fertility of the male in certain situations, it does have several limitations. Studies have shown that the total motile sperm count (volume $\times$ concentration $\times$ motility) has been the most predictive factor in determining fertility compared to volume, concentration, and motility individually [4].

\section{Limitations of Semen Analysis}

The female factor -About half of the infertile couples have a male component of infertility and only 30\% of infertility in couples is due to male factors alone [5]. Age is a strong factor that affects fertility in females. This is mainly due to a decrease in oocyte number and quality with age [6,7]. The WHO fifth edition manual (2010) used studies that did not emphasise female age [8]. Female age must be considered when talking about a couple's fertility. Males with poor quality sperm could conceive when their relative subfertility is compensated by a young female with a high probability of conception [9]. That same man may experience problems with conception if his partner is a 45-year-old woman. In this case, poor results in a semen analysis could skew physicians to believe that the male is the cause of the couple's infertility.

Guzick, et al. [10] studied the differences in semen parameters between fertile and infertile couples after excluding the female factor by fertility evaluation. They discussed that it is more appropriate to separate semen measurements into three groups: fertile, indeterminate, and sub fertile, rather than using a single reference value to delineate normal and abnormal values, as done in the current WHO guidelines [2010] (Table1).

\begin{tabular}{|c|c|c|c|}
\hline $\begin{array}{c}\text { Semen } \\
\text { measurement }\end{array}$ & $\begin{array}{c}\text { Sub fertile } \\
\text { range }\end{array}$ & $\begin{array}{c}\text { Indeterminate } \\
\text { range }\end{array}$ & $\begin{array}{c}\text { Fertile } \\
\text { range }\end{array}$ \\
\hline $\begin{array}{c}\text { Concentration } \\
10^{6} / \mathrm{mL}\end{array}$ & $<13.5$ & $13.5-48.0$ & $>48.0$ \\
\hline Motility \% & $<32$ & $32-63$ & $>63$ \\
\hline $\begin{array}{c}\text { Morphology \% } \\
\text { normal }\end{array}$ & $<9$ & $9-12$ & $>12$ \\
\hline
\end{tabular}

Table 1: Semen analysis.

Absolute predictors of fertility on semen analysis: Men with following findings on semen analysis are guaranteed to be infertile, and they are the only cases in which semen analyses can predict infertility with absolute certainty. Azoospermia, severe asthenospermia $(0 \%$ motility), or globozoospermia [11].

\section{Recent Advances}

Reactive Oxygen Species: Seminal oxidative stress (OS) and sperm DNA fragmentation (SDF) are two advanced sperm function tests that are increasingly used in the evaluation of infertile men. OS has recently been identified as a major mediator in the various causes of male infertility [12]. High levels of reactive oxygen species (ROS) are found in the semen samples of $25-40 \%$ of infertile men [13]. Elevated seminal ROS induce a state of OS that can cause sperm dysfunction through aggravating membrane lipid peroxidation, sperm DNA damage, and abortive apoptosis. These consequences can affect sperm structural and functional integrity thereby altering motility, morphology, count, and viability [14]. Most importantly is the OS effect on the integrity of sperm DNA, where OS provokes nucleotide modifications, DNA strand breaks and chromatin cross-linking that result in SDF [15]. An accurate measure of $O S$ is the oxidationreduction potential (ORP), which provides an overview of the redox system through assessment of the net balance between oxidants and reductions in any given medium. Higher levels of ORP and SDF are associated with worse sperm quality and provide reliable information synergising the predictive value of semen analysis during male fertility evaluation $[16,17]$.

Reactive oxygen species (ROS) or 'free radicals' are highly reactive oxygen-derived molecules. Included in this category are oxygen-centred radicals (hydroxyl radical, nitric oxide radical, and superoxide anion radical) and non-radical derivatives (hydrogen peroxide, peroxynitrite anion, and hypochlorous acid) [18]. They play an important role in cell signaling and homoeostasis. They are produced by the sperm cell in small quantities providing beneficial functional effects including initiation of sperm capacitation, regulation of sperm maturation, and enhancement of cellular signalling pathways [19]. However, high levels of ROS may have paradoxical effects on sperm function, ultimately resulting in infertility. Increased DNA damage and lipid peroxidation are noticeable effects of exaggerated ROS levels in seminal plasma. Several endogenous (immature spermatozoa, leucocytes, varicocele) and exogenous (testicular hyperthermia, environmental and habitual exposures) conditions have been recognised as potential causes of increased ROS production.ROS are counterbalanced by antioxidants that help maintain the equilibrium in the redox potential desired for optimal sperm function. Seminal fluid is rich in antioxidants that nourish and protect the sperm. They exist in two forms; an enzymatic 
and a non-enzymatic antioxidant system [20]. The enzymatic system is comprised of glutathione peroxidase, superoxide dismutase, and catalase. These enzymes are naturally occurring in the sperm cell or seminal plasma and are thought to originate from the prostate. The nonenzymatic system, on the other hand, is composed of multiple compounds that are consumed through diet or as supplements. Measures of OS have been added to the clinician's armamentarium to provide a better understanding of the true male fertility potential [21]. OS was also found to have a significant negative influence on semen parameters, fertilisation rate, embryonic development, and pregnancy rate [22,23]. Identifying and treating OS through either ROS reduction or antioxidant therapy appears to be an appealing tactic in infertility management. The effect of dietary antioxidant supplementation on sperm DNA integrity has been investigated in few studies [24, 25]. In general, these reports assessed antioxidant effect on small-sized samples and for short treatment durations; however, they did report a beneficial effect on measures of SDF.

Lifestyle factors and male fertility: Much of the past research was performed on retrospective data with their own inherent biases and limitations. The Longitudinal Investigation of Fertility and the Environment (LIFE) study was the first prospective study to analyse fertility factors in couples of unknown fertility status [26]. In their report, the authors detailed the negative effects of heavy occupational exertion -sperm concentration and total count; hypertension -strict morphology, and increasing total number of medications -sperm count [27]. Their second publication focused largely on correlations between semen quality and measures of obesity, with $82 \%$ of the overall male cohort being overweight or obese (body mass index [BMI] $\geq 25$ ) at baseline [28]. Findings included a linear decline in ejaculate volume associated with increasing BMI and waist circumference (WC). WC was also noted to have a negative relationship with total sperm count (TSC); no significant correlations with sperm concentration, motility, morphology, DNA integrity, or vitality were found. Overall, an increasing frequency of men with abnormal ejaculate volume, sperm concentration, and TSC were seen with increasing body size. A review in 2013, reported increased prevalence of oligospermia or azoospermia in overweight and obese men from an analysis of over 13,000 men [29]. In a larger obese cohort, three North American male infertility centers combined their prospectively collected data to analyse BMI and its relationship with semen and reproductive hormonal parameters. Of 4,440 men included, $45.1 \%$ were overweight and $23.3 \%$ were obese at the time of initial evaluation. BMI negatively impacted reproductive hormones, as expected, with the greatest absolute effect on Testosterone/Estradiol ratio (T/E). All semen parameters were found to have negative correlations with BMI with significance noted for ejaculate volume, sperm concentration, morphology, and total motile count on multivariate analyses. In an initial study of exercise and diet-based weight loss regimens, promising changes in male reproductive parameters were seen [30].

\section{Smoking}

Cigarette smoke contains $>7000$ chemicals, including highly carcinogenic tobacco-specific nitrosamines, [e.g.4(methylnitrosamino)-1-(3-pyridyl)-1-butanone and $\mathrm{N}$ nitrosonornicotine], polycyclic aromatic hydrocarbons (e.g. benzo[a]pyrene), and volatile organic compounds (e.g. benzene) [31]. Cigarette smokers have increased exposure to hazardous substances such as tar, nicotine (which is highly addictive), carbon monoxide, and heavy metals (e.g. cadmium and lead) [32]. Smoking is associated with leucocytospermia, a major endogenous source of reactive oxygen species (ROS). Moreover, tobacco smoke contains ROS at levels that can overwhelm the endogenous antioxidant defence. Increased seminal level $s$ of ROS in smokers expose spermatozoa to oxidative stress, consequently impairing sperm function and ultimately com-promising male fertility [33].

A large meta-analysis involving males from 26 countries concluded that smoking causes a decline in sperm quality in both fertile and infertile men [34]. Sperm concentration in male smokers was reported to be typically $13-17 \%$ lower than that of non-smokers [35]. Moreover, cigarette smoking has been negatively associated with sperm count, motility, and morphology. The decline in semen quality was found to be more marked in heavy ( $>20$ cigarettes/day) and moderate (1020 cigarettes/day) smokers compared to mild smokers (1-10 cigarettes/day). The effect size was higher in infertile males than in the general population [36]. Smoking is also associated with increase in DNA damage, aneuploidies, and mutations in sperm [37].

\section{Alcohol}

A recent meta-analysis involving 16395 men reported that alcohol intake has a detrimental effect on semen volume and sperm morphology [38]. Direct exposure of spermatozoa to alcohol (at concentrations corresponding to that of serum after moderate and heavy drinking) was found to be harmful to sperm motility and morphology in a dose-dependent manner [39]. Alcohol appears to interfere with the production of GnRH, FSH, LH, and 
testosterone, as well as impair the functions of Leydig and Sertoli cells. As a result, the production, morphological development and maturation of spermatozoa could be impaired. Partial or complete spermatogenic arrest and Sertoli cell-only syndrome were more commonly present amongst heavy drinker s compared to non-drinkers [40]. Both smoking and Alcohol consumption together appear to exert an additive effect that could adversely alter sperm parameters [41]. Other risk factors that could potentially influence sperm quality are use of illicit drugs, obesity, psychological stress, diet and caffeine intake.

\section{Sperm DNA Fragmentation}

An understanding of male infertility at the molecular level and the recognition of sperm DNA integrity has revived interest in sperm function tests in recent years. Emerging evidence on the role of sperm DNA integrity on reproductive out-comes and development of sperm DNA fragmentation (SDF) assays opens a new horizon in clinical Andrology. The value of this test has been acknowledged in the latest AUA and European Association of Urology (EAU) guidelines [42,43]. Infertile men usually have a larger proportion of sperm with higher levels of fragmented DNA than fertile men. Both intrinsic and extrinsic factors are involved in the pathogenesis of fragmented DNA. Poor chromatin structure renders the sperm vulnerable to DNA damage in the face of extrinsic factors. The lack of a DNA repair mechanism in sperm also explains its susceptibility to DNA fragmentation. Abortive apoptosis [44] and defective maturation [45] theories were proposed to explain the intrinsic factors in the generation of SDF in testicular sperm. However, there is evidence showing that there is more DNA fragmentation in epididymal and ejaculated sperm than in testicular sperm, suggesting extrinsic factors being more significant in most patients [46] Recently, oxidative stress has been identified as an important extrinsic cause of SDF. The presence of a large amount of polyunsaturated fatty acids in the plasma membrane makes sperm particularly susceptible to oxidative stress-mediated damage [47].

\section{Management of Elevated DNA Fragmentation}

One of the few male infertility treatment areas that have seen advances in the past several years has been the management of elevated DNA fragmentation index (DFI) in vitro fertilization (IVF)/intra cytoplasmic sperm injection (ICSI). Based on the concept that much of the DNA damage in ejaculated sperm occurs at the epididymal level, Greco et al. began exploring the use of surgically retrieved testicular sperm in couples with elevated DFI [48]. In 18 couples who had previously failed ICSI with ejaculated sperm, repeat ICSI was performed using testicular sperm. Sperm DFI rates proved to be much lower in the testicular samples and eight of 18 (44.4\%) couples were able to achieve a pregnancy with testicular sperm. The use of testicular sperm to optimize outcomes in couples with failed fertility attempts has gained popularity with several recent publications and research presentations [49]. A recent review of 147 couples undergoing IVF with elevated sperm DFI levels $(>30 \%$ on sperm chromatin dispersion assay despite oral antioxidant therapy) revealed significant reductions in DFI using testicular sperm over ejaculated specimens $(8.3 \%$ and $40.7 \%$, respectively) [50]. Significant improvements in clinical pregnancy $(51.9 \%$ versus $40.2 \%)$, miscarriage ( $10.0 \%$ versus $34.3 \%)$, and live birth (46.7\% versus $26.4 \%$ ) rates were also seen for the testicular-ICSI versus ejaculated- ICSI groups, respectively.

\section{Novel Biomarkers}

While various bodily fluids can be sampled to investigate novel fertility biomarkers, seminal plasma contains concentrated levels of proteins derived from the male reproductive system and may prove the most fruitful. Batruch, et al. was able to identify over 2,300individual proteins from semen samples of fertile and infertile men using mass spectrometry [51]. In a study by Diamandis, et al. prostaglandin D synthase (PGDS) levels were found to positively correlate with sperm concentration, motility, and morphology [52]. Various groups have started to compare seminal plasma proteomic profiles betweensmall cohorts of fertile and infertile men [53,54].

\section{Azoospermia}

Obstructive azoospermia (OA) and non obstructive azoospermia (NOA) needs to be differentiated for proper patient counselling and management in select circumstances of undetermined azoospermia. Folliclestimulating hormone (FSH) and testicular size are commonly used to predict between the two, though with limited sensitivity in some men [55]. Testicular biopsy is necessary to differentiate subtypes of NOA. Efforts from various research groups have identified a number of potential protein biomarkers including PGDS, acrosomal vesicle protein 1 (ACRV1), lectin galactoside-binding soluble 3 binding protein (LGALS3BP), extracellular matrix protein 1 (ECM1), and testis expressed 101 (TEX101). ECM1, an epididymal protein, was able to assess for vasal patency and discriminate between NOA and $0 A$ with $73 \%$ specificity at $100 \%$ sensitivity. TEX101, a testicular protein, aided in differentiating hypo 
spermatogenesis, maturation arrest, and Sertoli cell-only patterns of NOA. A combined assay using ECM1 and TEX101 is currently under development [56].

A review by Kovac, et al. has summarized a number of potential gene biomarkers [57]. Additionally, TEX11 mutations of the $\mathrm{X}$ chromosome were recently noted in an array comparative genomic hybridization study, affecting seven of 289 (2.4\%) screened men with NOA [58]. Using ORP and SDF measures in conjunction with standard semen morphology analysis could be used to validate the result of the fertility status of patients.

\section{Advances in Sperm Retrieval Techniques in Azoospermia}

Operative sperm retrieval is indicated in men with obstructive azoospermia (OA) if reconstruction is not possible, or has failed. In men with $\mathrm{OA}$, sperm may be retrieved percutaneously by percutaneous epididymal aspiration (PESA) [59] or by open surgical procedures, e.g. microsurgical epididymal sperm aspiration (MESA) [60], or the simpler procedure of open fine-needle aspiration (OFNA) that does not need an operating microscope [61], or by a single open testicular biopsy. In any case, sperm retrieval is easy and assured. The greater challenge is sperm retrieval in men with non-OA (NOA): only some of these men will have a few sperm in the testes, and the distribution of these scanty sperm may be multi-focal or very localised, necessitating different sperm-retrieval techniques.

\section{Efficacy of Sperm Retrieval}

All reviews found microdissection testicular sperm extraction (micro-TESE) to have the highest sperm retrieval rates. The systemic review by Deruyver, et al. [62] reported SRRs of $16.7-45 \%$ by conventional TESE (CTESE), vs $42.9 \%$ to $63 \%$ with micro-TESE. However, they found that micro-TESE was superior only in men with Sertoli cell- only syndrome, and that there was no statistical difference in SRR for men with maturation arrest. The meta-analysis by Bernie, et al. [63], compared SRR by testicular sperm aspiration (TESA), cTESE and micro- TESE. They found that cTESE was twice more likely to find sperm than TESA, and that micro-TESE was 1.5-times more likely to find sperm as compared to cTESE.

\section{Predictors of successful sperm retrieval}

There are conflicting reports on predictors of sperm retrieval. Some studies reported lower SRRs with high FSH [64], and small testes [65], whilst others found no corelation [66].

\section{Varicocele and Male Infertility}

Varicoceles have detrimental effects on semen quality, sperm function, and pregnancy outcomes in some men [67]. Oxidative stress seems to have a central role in the pathogenesis of varicocele-induced infertility [68]. After varicocelectomy there is decrease in sperm DNA fragmentation with increased pregnancy rate [69]. Varicocelectomy improves semen parameters, sperm function, and pregnancy outcomes in men from couples with documented infertility [70,71]. The optimal technique for performing varicocelectomy is a microsurgical approach, owing to reduced complication rates and increased pregnancy rates compared with other techniques [72]. Varicocelectomy might have beneficial effects on pregnancy outcomes following assisted reproduction [73].

\section{Conclusions}

Male infertility is a global health issue which is increasing in incidence in the world scenario. Incidence is higher in developing countries. Research in genetics, Proteomics has opened new vistas in the management of so called "Idiopathic Infertility. Still there is need for further research into underlying etiology and treatment of male infertility.

\section{References}

1. World Health Organization (1997) Towards more objectivity in diagnosis and management of male fertility. Intl J Androl 7(Suppl): 1-53.

2. Cavallini G (2006) Male idiopathic oligoasthenoteratozoospermia. Asian J Androl 8(2): 143-157.

3. Rolland M, Le Moal J, Wagner V, Royere D, De Mouzon J (2013) Decline in semen concentration and morphology in a sample of 26,609 men close to general population between 1989 and 2005 in France. Hum Reprod 28(2): 462-470.

4. Bonde JP, Ernst E, Jensen TK, Hjollund NH, Kolstad H, et al. (1998) Relation between semen quality and fertility: A population-based study of 430 firstpregnancy planners. Lancet 352(9135): 1172-1177.

5. Brugh VM, Lipshultz LI (2004) Male factor infertility: evaluation and management. Med Clin North Am 88: 367-385. 
6. Crawford NM, Steiner AZ (2015) Age-related infertility. Obstet Gynecol Clin North Am 42(1): 1525.

7. American College of Obstetricians and Gynecologists Committee on (2014) Gynecologic Practice and Practice Committee. Female agerelated fertility decline. Committee Opinion No. 589. Fertil Steril 101: 633-634.

8. Cooper TG, Noonan E, von Eckardstein S, Auger J, Baker HW, et al. (2010) World Health Organization reference values forhuman semen characteristics. Hum Reprod Update 16(3): 231-245.

9. Jungwirth A, Diemer T, Dohle GR, Giwercwan A, Kopa $\mathrm{Z}$, et al. (2015) Guidelines on male infertility. European Association of Urology.

10. Guzick DS, Overstreet JW, Factor-Litvak P, Brazil CK, Nakajima ST, et al. (2001) Sperm morphology, motility, and concentration in fertile and infertile men. N Engl J Med 345(19): 1388-1393.

11. Wang C, Swerdloff RS (2014) Limitations of semen analysis as a test of male fertility and anticipated needs from newer tests. Fertil Steril 102(6): 15021507.

12. Agarwal A, Virk G, Ong C, du Plessis SS (2014) Effect of oxidative stress on male reproduction. World J Mens Health 32(1): 1-17.

13. De Lamirande E, Gagnon C (1995) Impact of reactive oxygen species on spermatozoa: a balancing act between beneficial and detrimental effects. Hum Reprod 10: 15-21.

14. Sharma RK, Agarwal A (1996) Role of reactive oxygen species in male infertility. Urology 48(6): 835-850.

15. Sakkas D, Mariethoz E, Manicardi G, Bizzaro D, Bianchi PG, et al. (1999) Origin of DNA damage in ejaculated human spermatozoa. Rev Reprod 4(1): 3137.

16. Agarwal A, Majzoub A, Esteves SC, Ko E, Ramasamy R, et al. (2016) Clinical utility of sperm DNA fragmentation testing: practice recommendations based on clinical scenarios. Transl Androl Urol 5(6): 935-950.

17. Fernandez JL, Muriel L, Rivero MT, Goyanes V, Vazquez R, et al. (2003) The sperm chromatin dispersion test: a simple method for the determination of sperm DNA fragmentation. J Androl 24(1): 59-66.

18. Aitken RJ, Clarkson JS, Fishel S (1989) Generation of reactive oxygen species, lipid peroxidation, and human sperm function. Biol Reprod 41(1): 183-197.

19. Sies H (1993) Strategies of antioxidant defense Eur J Biochem 215 (2): 213-219

20. Tremellen $K$ (2008) Oxidative stress and male infertility-a clinical perspective. Hum Reprod Update 14(3): 243-258.

21. Agarwal A, Saleh RA, Bedaiwy MA (2003) Role of reactive oxygen species in the pathophysiology of human reproduction. Fertil Steril 79(4): 829-843.

22. Greco E, Iacobelli $M$, Rienzi L, Ubaldi $F$, Ferrero $S$, et al. (2005) Reduction of the incidence of sperm DNA fragmentation by oral antioxidant treatment. J Androl 26(3): 349-353.

23. Omu AE, Dashti H, Al-Othman S (1998) Treatment of as the no zoospermia with zinc sulphate: andrological, immunological and obstetric outcome. Eur J Obstet Gynecol Reprod Biol 79(20: 179-184.

24. Palmer NO, Bakos HW, Fullston T, Lane M (2012) Impact of obesity on male fertility, sperm function and molecular composition. Spermatogenesis 2(4): 253-263.

25. Buck Louis GM, Schisterman EF, Sweeney AM, Wilcosky TC, Gore-Langton RE, et al. (2011) Designing prospective cohort studies for assessing reproductive and developmental toxicity during sensitive windows of human reproduction and development--the LIFE Study. Paediatr Perinat Epidemiol 25(5): 413-424.

26. Eisenberg ML, Chen Z, Ye A, Buck Louis GM (2015) Relationship between physical occupational exposures and health on semen quality: data from the Longitudinal Investigation of Fertility and the Environment (LIFE) Study. Fertil Steril 103(5): 12711277.

27. Eisenberg ML, Kim S, Chen Z, Sundaram R, Schisterman EF, et al. (2014) The relationship between male BMI and waist circumference on semen quality: data from the LIFE study. Hum Reprod 29(2): 193-200. 
28. Sermondade N, Faure C, Fezeu L, Shayeb AG, Bonde JP, et al. (2013) BMI in relation to sperm count: an updated systematic review and collaborative metaanalysis. Hum Reprod Update 19(3): 221-231.

29. Bieniek JM, Kashanian JA, Deibert CM, Grober ED, Lo $\mathrm{KC}$, et al. (2016) Influence of increasing body mass index on semen and reproductive hormonal parameters in a multi-institutional cohort of subfertile men. Fertil Steril 106(5): 1070-1075.

30. Håkonsen LB, Thulstrup AM, Aggerholm AS, Olsen J, Bonde JP, et al. (2011) Does weight loss improve semen quality and reproductive hormones? Results from a cohort of severely obese men. Reprod Health 8: 24 .

31. Centres for Disease Control and Prevention (US) National Centre for Chronic Disease Prevention and Health Promotion (US) Office on Smoking and Health (US). How tobacco smoke causes disease: the biology and behavioural basis for smoking-attributable disease: a report of the Surgeon General Publications and Reports of the Surgeon General. Atlanta (GA): Centres for Disease Control and Prevention (US), 2010.

32. Dai JB, Wang ZX, Qiao ZD (2015) the hazardous effects of tobacco smoking on male fertility. Asian J Androl 17: 954-960.

33. Harlev A, Agarwal A, Gunes SO, Shetty A, du Plessis SS, et al. (2015) du Plessis SS. Smoking and male infertility: an evidence-based review. World J Mens Health 33(3): 143-160.

34. Li Y, Lin H, Li Y, Cao J (2011) Association between socio-psycho-behavioral factors and male semen quality: systematic review and meta-analyses. Fertil Steril 95(1): 116-123.

35. Vine MF, Margolin BH, Morrison HI, Hulka BS (1994) Cigarette smoking and sperm density: a metaanalysis. Fertil Steril 61(1): 35-43.

36. Sharma R, Harlev A, Agarwal A, Esteves SC (2010) Cigarette smoking and semen quality: a new metaanalysis examining the effect of the 2010 world health organization laboratory methods for the examination of human semen. Eur Urol 70(4): 635645.

37. Beal MA, Yauk CL, Marchetti F (2017) From sperm to offspring: Assessing the heritable genetic consequences of paternal smoking and potential public health impacts. Mutat Res 773: 26-50.

38. Ricci E, Al Beitawi S, Cipriani S, Candiani M, ChiaffarinoF, et al. (2017) Semen quality and alcohol intake: a systematic review and meta-analysis. Reprod Biomed Online 34(1): 38-47.

39. Donnelly GP, McClure N, Kennedy MS, Lewis SE (1999) direct effect of alcohol on the motility and morphology of human spermatozoa. Andrologia 31(1): 43-47.

40. Emanuele MA, Emanuele NV (1998) Alcohol's effects on male reproduction. Alcohol Health Res World 22(3): 195-201.

41. Martini AC, Molina RI, Estofán D, Senestrari D, Fiol de Cuneo M, et al. (2004) Effects of alcohol and cigarette consumption on human seminal quality. Fertil Steril 82(2): 374-377.

42. Jarrow J, Sigman M, Kolettis PN, Lipshultz LR, McClure RD, et al. (2011) Optimal Evaluation of the Infertile Male. AUA Best Practice Statement reviewed and validity confirmed.

43. Jungwirth A, Diemer T, Kopa Z, Krausz C, Tournaye H, et al. (2017) Male Infertility. EAU Guidelines.

44. Sakkas D, Mariethoz E, Manicardi G, Bizzaro D, Bianchi PG, et al. (1999) Origin of DNA damage in ejaculated human spermatozoa Bianchi and $U$ Bianchi. Rev Reprod 4(1): 31-37.

45. Sakkas D, Manicardi G, Bianchi PG, Bizzaro D, Bianchi UR, et al. (1995) Relationship between the Presence of Endogenous Nicks and Sperm Chromatin Packaging in Maturing and Fertilizing Mouse Spermatozoa . Biology of Reproduction 52(1): 11491155.

46. Esteves SC, Sánchez-Martín F, Sánchez-Martín P , Schneider DT, Gosálvez J (2015) Comparison of reproductive outcome in oligozoospermic men with high sperm DNA fragmentation undergoing intracytoplasmic sperm injection with ejaculated and testicular sperm. Fertility and Sterility. 104(6): 1398 1405.

47. Aitken RJ, Clarkson JS (1987) Cellular basis of defective sperm function and its association with the genesis of reactive oxygen species by human spermatozoa. J Reprod Fertil 81(2): 459-469. 
48. Greco E, Scarselli F, Iacobelli M, Rienzi L, Ubaldi F, et al. (2005) Efficient treatment of infertility due to sperm DNA damage by ICSI with testicular spermatozoa. Hum Reprod 20(1): 226-230.

49. Kovac JR, Lipshultz LI (2016) Use of testicular sperm to combat the negative effects of DNA fragmentation. Asian J Androl 18(3): 434.

50. Esteves SC, Sánchez-Martín F, Sánchez-Martín P, Schneider DT, Gosálvez J (2015) Comparison of reproductive outcome in oligozoospermic men with high sperm DNA fragmentation undergoing intracytoplasmic sperm injection with ejaculated and testicular sperm. Fertil Steril 104(6): 1398-405.

51. Batruch I, Lecker I, Kagedan D, Smith CR, Mullen BJ, et al. (2011) Proteomic analysis of seminal plasma from normal volunteers and post-vasectomy patients identifies over 2000 proteins and candidate biomarkers of the urogenital system. J Proteome Res 10(3): 941-953.

52. Diamandis EP, Arnett WP, Foussias G, Pappas H, Ghandi S, et al. (1999) Seminal plasma biochemical markers and their association with semen analysis findings. Urology 53(3): 596-603.

53. Milardi D, Grande G, Vincenzoni F, Messana I, Pontecorvi A, et al. (2012) Proteomic approach in the identification of fertility pattern in seminal plasma of fertile men. Fertil Steril 97(1): 67-73.

54. Cadavid JAP, Alvarez A, Markert UR, Walter Cardona Maya (2014) Differential protein expression in seminal plasma from fertile and infertile males. J Hum Reprod Sci 7(3): 206-211.

55. Bieniek JM, Drabovich AP, Lo KC (2016) Seminal biomarkers for the evaluation of male infertility. Asian J Androl 18(3): 426-433.

56. Drabovich AP, Dimitromanolakis A, Saraon P, Soosaipillai A, Batruch I, et al. (2013) Differential diagnosis of azoospermia with proteomic biomarkers ECM1 and TEX101 quantified in seminal plasma. Sci Transl Med 5(212): 212ra160.

57. Kovac JR, Pastuszak AW, Lamb DJ (2013) The use of genomics, proteomics, and metabolomics in identifying biomarkers of male infertility. Fertil Steril 99(4): 998-1007.

58. Yatsenko AN, Georgiadis AP, Röpke A, Andrea J Berman, Thomas Jaffe, et al. (2015) X-linked TEX11 mutations, meiotic arrest, and azoospermia in infertile men. N Engl J Med 372(22): 2097-2107.

59. Kovac JR, Lehmann KJ, Fischer MA (2014) A singlecenter study examining the outcomes of percutaneous epididymal sperm aspiration in the treatment of obstructive azoospermia. Urol Ann 6: 41-45.

60. Girardi SK, Schlegel P (1996) MESA: review of techniques, preoperative considerations and results. J Androl 17: 5-9.

61. Shah RS (2002) Surgical and non-surgical methods of sperm retrieval. In: Hansotia M, Desai S, Parihar M (Eds.), Advanced infertility management. New Delhi, Jaypee Brothers, pp: 253-258.

62. Deruyver Y, Vanderschueren D, Van der Aa F (2014) Outcome of microdissection TESE compared with conventional TESE in non-obstructive azoospermia: a systematic review. Andrology 2: 20-24.

63. Bernie AM, Mata DA, Ramasamy R, Schlegel PN (2015) Comparison of microdissection testicular sperm extraction, conventional testicular sperm extraction, and testicular sperm aspiration for nonobstructive azoospermia: a systematic review and meta-analysis. Fertil Steril 104: 1099-1103.

64. Colpi GM, Colpi EM, Piediferro G, Giacchetta D, Gazzano G, et al. (2009) Microsurgical TESE versus conventional TESE for ICSI in non-obstructive azoospermia: a randomized controlled study. Reprod Bio Med Online 18(3): 315-319.

65. Ghalayini IF, Al-Ghazo MA, Hani OB, Al-Azab R, BaniHani I, et al. (2011) Clinical comparison of conventional testicular sperm extraction and microdissection techniques for non-obstructive azoospermia. J Clin Med Res 3: 124-131.

66. Vernaeve V, Tournaye H, Schiettecatte J, Verheyen G, Van Steirteghem A, et al. (2002) Serum inhibin B cannot predict testicular sperm retrieval in patients with non-obstructive azoospermia. Hum Reprod 17: 971-976.

67. Damsgaard J, Joensen UN, Carlsen E, Erenpreiss J, Blomberg Jensen $M$, et al. (2016) Varicocele is associated with impaired semen quality and reproductive hormone levels: a study of 7035 healthy young men from six European countries. Eur Urol 70(6): 1019-1029. 
68. Wang YJ, Zhang RQ, Lin YJ, Zhang RG, Zhang WL (2012) Relationship between varicocele and sperm DNA damage and the effect of varicocele repair: a meta-analysis. Reprod Biomed Online 25: 307-314.

69. Smit M, Romijn JC, Wildhagen MF, Veldhoven JL, Weber RF, et al. (2013) Decreased sperm DNA fragmentation after surgical varicocelectomy is associated with increased pregnancy rate. J Urol 183: 270-274.

70. Baazeem A, Belzile E, Ciampi A, Dohle G, Jarvi K, et al. (2011) Varicocele and male factor infertility treatment: a new meta-analysis and review of the role of varicocele repair. Eur Urol 60(4): 796-808.

71. Abdel-Meguid TA, Al-Sayyad A, Tayib A, Farsi HM (2011) Does varicocele repair improve male infertility? An evidence-based perspective from a randomized, controlled trial. Eur Urol 59(3): 455-461.

72. Ding H, Tian J, Du W, Zhang L, Wang H, et al. (2012) Open non-microsurgical, laparoscopic or open microsurgical varicocelectomy for male infertility: a meta-analysis of randomized controlled trials. BJU Int 110: 1536-1542.

73. Kirby EW, Wiener LE, Rajanahally S, Crowell K, Coward RM (2016) Undergoing varicocele repair before assisted reproduction improves pregnancy rate and live birth rate in azoospermic and oligospermic men with a varicocele: a systematic review and meta-analysis. Fertil Steril 106: 13381343.

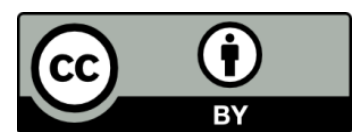

